African Crop Science Journal by African Crop Science Society is licensed under a Creative Commons Attribution 3.0 Uganda License. Based on a work at www.ajol.info/ and www.bioline.org.br/cs DOI: http://dx.doi.org/10.4314/acsj.v25i2.8

\title{
INSECT ANTAGONISTIC BIO-INOCULANTS FOR NATURAL CONTROL OF LEAF-MINING INSECT PESTS OF FRENCH BEANS
}

\author{
J. AKELLO ${ }^{1,3}$, A. CHABI-OLAYE ${ }^{2}$ and R.A. SIKORA ${ }^{3}$ \\ ${ }^{1}$ International Institute of Tropical Agriculture (IITA-Zambia), Plot 1458B Ngwerere Road, P. O. Box 310142, \\ Chelston, Lusaka, Zambia \\ ${ }^{2}$ International Centre of Insect Physiology and Ecology (ICIPE), P. O. Box 30772-00100, Nairobi, Kenya \\ ${ }^{3}$ INRES-Molecular Phytomedicine, University of Bonn, Karlrobert-Kreiten-Straße 13 D-53115, \\ Bonn, Germany \\ Corresponding author: j.akello@ cgiar.org
}

(Received 31 January, 2017; accepted 26 May, 2017)

\begin{abstract}
Fungal endophytes, specifically, Trichoderma asperellum, Beauveria bassiana and Metarhizium anisopliae; strains M2RT4, S4SU1 and S4ST7, respectively, are known to deter aphid infestation and damage to leguminous crops, but no research exists on their biochemical profiles and effects on French bean (Phaseolus vulgaris) leaf miners. The objective of this study was to assess the ability of these endophytic bio-inoculants to produce extracellular enzymes, as well as determine their impact on French beans seedling emergence and growth, and leaf miner fecundity and pupation. Laboratory and greenhouse experiments were conduct at the International Centre of Insect Physiology and Ecology (ICIPE, Nairobi), and the University of Bonn (Germany). Bio-priming French bean seeds by soaking in fungal suspension containing $10^{8}$ conidia/ $\mathrm{ml}$ for $4 \mathrm{hr}$ positively impacted on seedling vigour. Six weeks after germination, all bio-inoculant treatments improved nodulation by 1.5-1.7 folds, while S4SU1 and M2TR4 improved shoot biomass by 2g. In vitro, spore suspensions of these isolates were highly toxic to leaf miner larvae, often resulting in high mortalities and a suppression of pupation by over $70 \%$. All tested isolates exhibited protease (Index=1.22), lipase (Index=1.32) and cellulase (Index=1.06) activities; with $M$. anisopliae being the best enzyme secretor when cultured under dark conditions on enzyme-specific substrate for 7-14 days. In vivo B. bassiana-primed seedlings deterred larval feeding and development, resulting in reduced number of larvae, pupae and adults, by $65.3,43.2$ and 54.0\%, respectively. For the first time, this study showed that bio-priming French bean seeds with bio-inoculants can boost $P$. vulgaris growth and nodulation, consequently altering its interaction and response to leaf miner infestation, feeding and damage to treated seedlings. These bioinoculants, thus, hold great potential as crop protection agents and could be safely used for priming seeds prior to planting, if leaf mining damages and associated yield losses in French beans are to be minimised in an environmentally sound manner. Further studies should be undertaken to elucidate the mechanisms involved in plant growth promotion, nodulation and insect feeding deterrence.
\end{abstract}

Key Words: Bio-priming, endophytes, Liriomyza spp., nodulation

\section{RÉSUMÉ}

Les endophytes fongiques, spécialement, Trichoderma asperellum, Beauveria bassiana et Metarhizium anisopliae; souches M2RT4, S4SU1 et S4ST7, respectivement, sont connues pour dissuader l'infestation et le dommage des aphids sur les plantes légumineuses, mais aucune recherche n'a été menée sur leurs profils biochmiques et leurs effets sur les insectes mineurs de feuilles du haricot vert (Phaseolus vulgaris). L'objectif de cette étude était 
d'évaluer la capacité endophytique de ces bio-inoculants à produire des enzymes extra-cellulaires, ainsi que de déterminer leurs impacts sur l'émergence et la croissance des plantules du haricot vert, sur la fécondité et la nymphose du mineur des feuilles. Des expérimentations de laboratoire et sous serre on été conduites au Centre International de Physiologie et d'Ecologie d'Insecte (ICIPE, Nairobi), et à l'Université de Bonn (Allemagne). Le bio-amorçage des graines du haricot vert par trempage dans une suspension fongique contenant $10^{8}$ conidies $/ \mathrm{ml}$ pendant 4 heures a positivement imapcté la vigueur des plantules. Six semaines après la germination, tous les traitements de bio-inoculants ont augmenté la nodulation par 1,5-1,7 fois, pendant que S4SU1 et M2TR4 ont augmenté la biomasse des pousses d'environ $2 \mathrm{~g}$. En conditions in vitro, les suspensions de spores de ces isolats étaient fortement toxiques aux larves des mineurs de feuilles, régulièrement provoquant de grandes mortalités et une suppression de la nymphose de plus de $70 \%$. Tous les isolats testés ont produit des activités protease (indice=1,22), lipase (indice=1,32) et cellulase (indice=1.06); avec $M$. anisopliae constiuant le meilleur sécreteur d'enzyme alors qu'il est cultivé dans le noir sur un substrat d'enzyme spécifique pendant 7-14 jours. En conditions in vitro, les plantules amorcées avec B. bassiana ont freiné l'alimentation et le développement des larves, résultant en une réduction du nombre de larves, nymphes et adultes, par 65,3; 43,2; et 54,0\%, respectivement. Pour une première fois, cette étude a montré que le bio-amorçage des graines du haricot vert avec des bioinoculants peut augmenter la croissance et la nodulation de $P$. vulgaris, par conséquent altère son interaction et sa réponse à l'infestation, à l'alimentation de mineur de feuilles et les dommages sur les plantules traitées. Ces bioinoculants, constituent ainsi de grands potentiels agents protecteurs de cultures et pourraient être utilisés de façon sécurisante pour l'amorçage des graines avant leur semis, si les dommages causés sur les feuilles et la perte de rendement associée sur le haricot vert sont à réduire sans danger pour l'environnement. Des études supplémentaires devraient être menées pour élucider les mécanismes impliqués dans la promotion de la croissance végétale, la nodulation et la dissuasion de l'alimentation de l'insecte.

Mots Clés: Bio-amorçage, endophytes, Liriomyza spp., nodulation

\section{INTRODUCTION}

In sub-Saharan Africa, common bean (Phaseolus vulgaris $\mathrm{L}$.) plays an important role in sustaining food security and soil health. The crop is not only valued for richness in proteins, calories and micronutrients; but is also key to supporting nitrogen fixation in the soil and enhancing incomes of millions of rural farm households in the region (Broughton et al., 2003; Wortmann et al., 2004).

Africa with average annual production of 2.5 million metric tonnes is the second largest producer of common bean, with Uganda being among the top 10 producers on the continent. Despite its importance, bean production in this region is severely constrained by abiotic and biotic factors, among which are high incidences of pest and diseases (Wagara and Kimani, 2007; Birachi et al., 2011; Beebe et al., 2013).

Among the insect pests constraining bean production, leaf miners particularly the vegetable leaf miner (Liriomyza sativae (Blanchard)) and the American serpentine leaf miner (L. trifolii (Burgess)) (Diptera: Agromyzidae), are considered economically important in sub-Saharan Africa (Chabi-Olaye et al., 2008). The larvae feed on the leaf parenchyma, which reduces the photosynthetic leaf area and provides entry points for foliar pathogens. Infested and injured leaves become necrotic, and may drop prematurely, leading to poor yields.

According to Andrew and Hughes (2005), climate change is expected to have negative impacts on agriculture by increasing insect pest outbreaks. Consequently, pesticide use may rise leading to negative environmental, health and economic impacts. The potential health hazards associated with increased use of pesticides, and development of insect resistance calls for use of other environmentally sound peat management methods.

Recently, microbially based bio-inoculants, including mycorrhiza and endophytic bacteria or fungi, have been tested and found to be effective in abating some biotic and abiotic constraints to crop production (Begum et al., 
2010; Pill et al., 2011; Labidi et al., 2015). Bio-priming is a process by which seeds or seedlings are hydrated in a spore suspension of beneficial biological organisms. It has has been found to promote rapid early seedling establishment, as well as offer protection against pathogens and pests (Huong et al., 2009; Begum et al., 2010; Pill et al., 2011). Begum et al. (2010), for instance, showed that bio-priming soybean seeds with Pseudomonas aureofaciens enhanced seed germination by $32.4-60 \%$ and promoted vigorous seedling stand by $56-73.9 \%$. Also, application of microbial inoculants to seed and/or transplants was reported to enhance plant tolerance to soil borne pests (Sikora et al., 2008; Huong et al., 2009) and plant pathogens (Mathre et al., 1994; Pill et al., 2011; El-bab et al., 2013).

In other studies, the use of bio-inoculants was demonstrated to induce systemic resistance against sucking, mining and stem boring insect pests (Martinuz et al., 2012a, 2012b; Akello and Sikora, 2012; Akutse et al., 2013). Bio-priming faba beans (Vicia faba) with endophytic fungal isolates belonging to the genus Beauveria, Trichoderma and Gibberella, for example, was reported to reduce aphid fecundity, lengthen nymph developmental time, as well as protect bean seedlings from aphid attack (Akello and Sikora, 2012). Akutse et al. (2013) and Akello and Sikora (2012) demonstrated that treating faba beans with the same isolates reduced the vegetable leaf miner (L. hudobriendsis) and the black bean aphid (Aphis fabae) fecundity, respectively. However, studies that have investigated the relationship between endophyte infection and leaf miner performance reveal that leaf miner response to microbial inoculants is highly dependent on the season, host plant, endophyte species as well as leaf miner species (Faeth and Hammon, 1997; Gange et al., 2007).

The objective of this study was to investigate the enzymatic profiles of three endophytic bio-inoculants, as well as their impact on seedling emergence and growth of
French beans and leaf miner fecundity and pupation.

\section{MATERIALS AND METHODS}

Research site and design. Laboratory and greenhouse experiments were conducted to assess the in vitro and in vivo effects of three endophytic fungi, Beauveria bassiana (Balsamo) Vuillemin, Metarhizium anisopliae (Metschnikoff) and Trichoderma asperellum (Samuels, Liechfeldt et Nirenberg)), on seedling growth, and leaf miner fecundity and pupation. The endophytes were isolated from stems and roots of healthy maize plants (Akello, 2012).

Another set of assays was undertaken to determine the biochemical properties of these endophytic fungi. The studies were conducted at the International Center of Insect Physiology and Ecology (ICIPE, Nairobi) and the Institute of Crop Science and Resource Conservation (INRES), (University of Bonn, Germany).

For the in vivo assays, five different experiments were set up. Each invivo experiment, consisted of four treatments, namely endophytic fungal strains, $B$. bassiana (S4SU1), M. anisopliae (S4ST7), $T$. asperellum (M2RT4) and a water control. All the experiments were organised in a completely randomised design and repeated twice.

The French bean variety, Rosecoco was used in all the experiments. Rosecoco is a bushy common bean variety that is commonly grown in Uganda and Kenya. When mature, Rosecoco beans appear as medium-sized grains with deep red marks.

Bio-inoculants preparation. The endophytic strains used in the study were B. bassiana, M. anisopliae and T. asperellum strains S4SU1, S4ST7 and M2RT4, respectively; that were previously found to have detrimental effects on aphid development under greenhouse conditions (Akello and Sikora, 2012). Each strain was cultured on malt extract peptone 
agar (MEA) (Merck, Darmstadt, Germany), for 7-10 days, and harvested following procedures described by Akello and Sikora (2012). The harvested fungal suspension was vortexed, filtered on sterile Mira cloth and spore counts determined using an improved Neubauer hemocytometer. Conidial concentration was adjusted to $10^{8}$ conidia per $\mathrm{ml}$ using sterile water containing $0.02 \%$ Tween20.

Insect rearing. Insect rearing was a continuous process and the two leaf miner species, Liriomyza sativae and $L$. trifolii, were obtained from the ICIPE insectary and reared on French bean (Phaseolus vulgaris L.) var. Rosecoco in insect cages at $26 \pm 2{ }^{\circ} \mathrm{C}$, photoperiod of 12L:12D, and relative humidity of about $40 \%$. The first colonies of leaf miners originated from adult leaf miners collected from wild crucifers at the ICIPE campus $\left(01^{\circ} 13.32\right.$ S $36^{\circ} 53.82 \mathrm{E}, 1600 \mathrm{~m}$ a.s.1.) and have been passed through more than 8 generations on $V$. faba. Prior to exposure to adult leaf miners, the beans were grown in the greenhouse for two weeks and then transferred to exposure cages containing adult flies of mixed sexes. The adults were allowed to feed and oviposit on the bean leaves for $48 \mathrm{~h}$ and the bean seedlings transferred to holding cages for 4-7 days.

To generate adult fly population, leaves containing mature larvae and/or pupae were harvested and incubated under laboratory conditions, i.e at $24 \pm 2{ }^{\circ} \mathrm{C}$, and relative humidity of $\sim 77 \%$ for $2-3$ days. The pupae were harvested from the leaves using a camel hair brush; transferred to vials with perforated lids and incubated in hatching cages at room temperature till adult emergence. Emerging adults were fed on $30 \%$ sucrose solution.

\section{Bioassays}

In vitro pathogenicity assay against Liriomyza. Four days after infesting 10 day old Rosecoco bean seedlings with adult leaf miner flies, the leaves were visually screened for the presence of mines. Leaves containing larvae were selected and the number of larvae per leaf counted using a bacterial colony counter. The leaves were gently washed under running tap water, dried on paper towels and randomly assigned to treatments.

Each selected leaf was dipped in a fungal spore suspension containing $10^{8}$ conidia $\mathrm{ml}^{-1}$ for $5 \mathrm{~min}$. Leaves of the control treatments were dipped in sterile distilled water for the same period of time. Treated leaves were transferred individually onto tap water agar plates, with three plates used per treatment. These were incubated for 4-5 days at room temperature, prior to pupal emergence assessment. During the assessment, the number of larvae and pupae were recorded. The proportion of pupae emerging was calculated as follows:

$$
\text { Pupal emergence }=\frac{\text { Total number of pupae }}{\text { Total number of larvae }} \times 100
$$

Enzymatic profiles of bio-inoculants. The ability of the endophytic fungal isolates, S4ST7, S4SU1 and M2RT4, to produce extracellular enzymes was tested on special media, amended with enzyme-specific substrates. To detect the production of protease enzyme, gelatin was used as the protein substrate (Hankin and Anagnostakis, 1975). The medium for assessing chitinase activity was prepared following procedures of Hsu and Lockwood (1975). To assess the production of lipases, sorbitan monolaurate (Tween 20, Sigma, MO, USA) was used as the lipid substrate (Sierra, 1957) at a rate of $1 \%$. For the assessment of cellulases, fungal isolates were inoculated on carboxymethyl cellulose (CMC) medium (Andro et al., 1984). Media lacking gelatin, chitin, Tween 20 and CMC acted as control plates for the protease, chitinase, lipase and cellulase, respectively. All the media were prepared, autoclaved at 121 ${ }^{\circ} \mathrm{C}$ for $15 \mathrm{~min}$, cooled and dispensed into 90 $\mathrm{mm}$ diameter $(\varnothing)$ Petri dishes. 
For each isolate, $5 \mathrm{~mm}$ diameter mycelial discs were obtained from the 7 day old PDA cultures, using a cork borer. The discs were placed singly at the centre of the agar plates. For each enzyme assay and isolate, a total of 5 culture plates amended with the enzymespecific substrate, were used; while 5 plates lacking the substrate served as controls. The inoculated plates were incubated at $25{ }^{\circ} \mathrm{C}$ under dark conditions for up to 14 days, except for M2RT4 isolate in which measurements were taken on the third day after plating. Degradation of the enzyme-specific substrate was detected by examining the presence of a clear zone (halo) around the fungal colony (Fig. 1).

To observe proteolytic activity, the plates were flooded with a saturated solution of ammonium sulphate, 7 days after incubation. For cellulytic activity, the 7-day old plates were flooded with $0.1 \%$ Congo red for $15 \mathrm{~min}$, washed with $1 \mathrm{M} \mathrm{NaCl}$ solution prior to taking the measurements. For lipases, a visible precipitate followed by a clearing around the fungal colonies after 7-14 days indicated positive results. The diameter of the fungal colony was measured exclusive and inclusive of the surrounding halo for all positive plates.

Bio-priming and seedling viability. The effects of S4ST7, S4SU1 and M2RT4 isolates on the germination of bean seeds were evaluated in vitro. French bean seeds, var. Rosecoco, were surfaced sterilised by soaking in $75 \%$ ethanol, for $1 \mathrm{~min}$. After that, the ethanol was discarded and $1.5 \%$ sodium hypoclorite added. The seeds were soaked for $3 \mathrm{~min}$ in hypochlorite solution, and rinsed three times in sterile distilled water, prior to treating with the fungal suspension. For each treatment, 15 seeds were soaked in $50 \mathrm{ml}$ spore suspension containing $10^{8}$ conidia per $\mathrm{ml}$ or in sterile water (controls), for $4 \mathrm{hr}$. The bioprimed bean seeds were planted in sterile sand (autoclaved at $121{ }^{\circ} \mathrm{C}$ for $1 \mathrm{hr}$ ) in $90 \mathrm{~mm}$ diameter Petri dishes. In total, 50 seeds were used, with 10 seeds sown per dish. The number of germinated seeds was counted 3 days after planting. The experiment was repeated two times.

Bio-priming, seedling growth and nodulation. French bean seeds of var. Rosecoco, were surfaced sterilised as described above. Fungal suspension of S4ST7, S4SU1 and M2RT4 cultures were prepared and adjusted to $10^{8}$ conidia per $\mathrm{ml}$. Surface sterilised seeds (15 seeds) were soaked in $50 \mathrm{ml}$ of fungal suspension for $4 \mathrm{hr}$, before planting in sterile soil. The soil substrate comprised of field soil containing $14.6 \%$ clay, $77.6 \%$ silt and $7.8 \%$ sand. Prior to use, the soil was sieved through a $2 \mathrm{~mm}$ diameter sieve to remove large particles and stones, mixed with
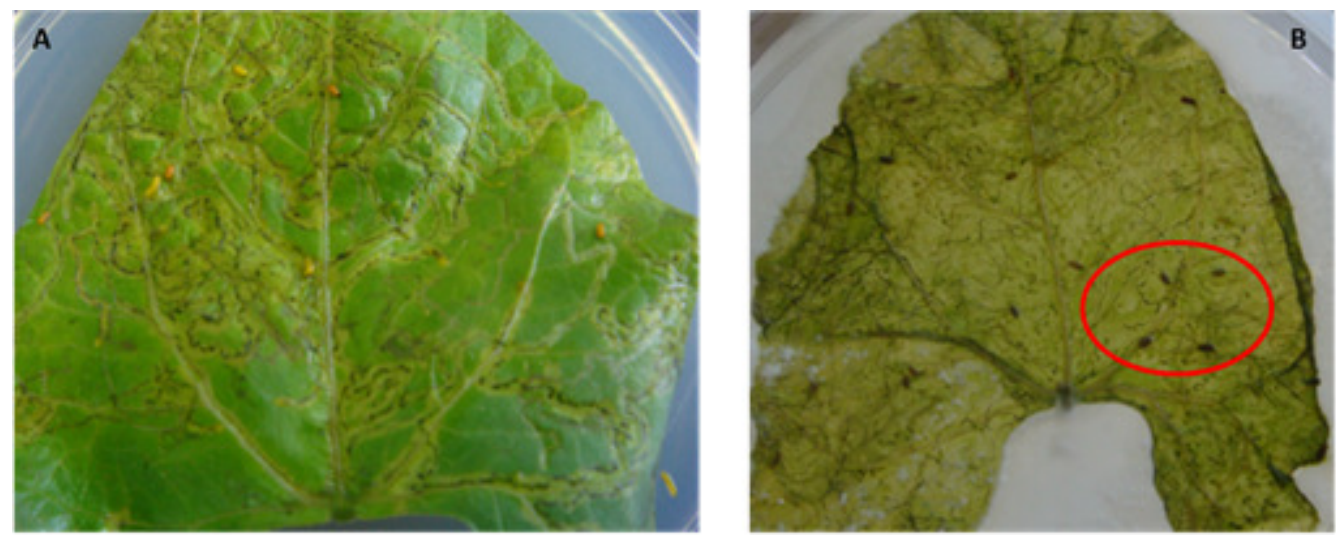

Figure 1. Blackening effects of dipping Liriomyza larval-infested leaves in spore suspension of fungal endophytes 3 days after treatment. $\mathrm{A}=$ control and $\mathrm{B}=$ endophyte-treated leaves. 
sand in a ratio of $1: 2(\mathrm{v} / \mathrm{v})$, autoclaved at $121^{\circ} \mathrm{C}$ for $60 \mathrm{~min}$, and then cooled for 48 hr.

Plastic pots $(0.51)$ were filled with the sterile soil and three treated seeds planted in each pot. Seeds used as controls were soaked in sterile distilled water for the same period of time before planting. For every treatment, five pots were used. The pots were watered daily and maintained under greenhouse conditions $\left(24 \pm 4{ }^{\circ} \mathrm{C}\right.$ and photoperiod of $16 \mathrm{hr}$ light) for two weeks; and the seedlings thinned to leave one seedling per pot.

After thinning, the seedlings were kept in the greenhouse for an additional 4 weeks; before the plants were harvested. Prior to harvesting, the relative chlorophyll index (CI) of the second youngest fully opened leaf of each plant was assessed using the SPAD-502 Plus chlorophyll meter (Spectrum Technologies, Inc., Illinois, USA). The SPAD calculates an index in 'SPAD units' based on absorbance at 650 and $940 \mathrm{~nm}$; with accuracy of \pm 1.0 SPAD units. For each leaf, 10 measurements were taken and the arithmetic mean of these measurements obtained for use in subsequent analyses. After that, the plants were removed from the soil substrate and the roots washed under running tap water until all the soil particles were removed. The roots were cut off from the stems with a knife, dried on tissue towels and then fresh shoot and root weights taken for each plant. Additionally, the number of root nodules was counted and recorded for each seedling. The experiment was repeated two times.

Bio-priming on oviposition, pupation and adult emergence. In this experiment, bean seeds were surface sterilised and primed with fungal suspension of S4ST7, S4SU1 and M2RT4 isolates or sterile water as described above. For each experiment, three seeds were sown in sterile soil in 0.51 pots. Five replicates organised in a completely randomised design were used per treatment. Seeded pots were maintained in the greenhouse $\left(24 \pm 4{ }^{\circ} \mathrm{C}\right.$ and photoperiod of $12 \mathrm{hr}$ light) for ten days, during which they were watered daily. The seedlings were then thinned to leave one per pot. The pots were randomly transferred into transparent oviposition cages.

The seedlings were infested with 2003 day-old adult flies of mixed sexes; and each treatment replicated five times for each species. The oviposition cages were kept under room conditions.

For the oviposition experiment, the plants were removed from the oviposition cage and the number of eggs counted $48 \mathrm{hr}$ after exposure. Prior to counting the eggs, two fully developed leaves showing signs of leaf miner feeding were detached from the mother plant and then boiled in a staining solution for $5 \mathrm{~min}$. The staining solution comprised of distilled water $(100 \mathrm{ml})$, lactic acid $(100 \mathrm{ml})$, glycerol $(200 \mathrm{ml})$, phenol $(100 \mathrm{ml})$ and acid fuschin $(0.5 \mathrm{~g})$. The stained leaves were transferred onto $90 \mathrm{~mm}$ diameter Petri dishes, cooled for $5 \mathrm{~min}$ and then rinsed thrice in warm water $\left(35 \pm 3^{\circ} \mathrm{C}\right)$. For each rinsing, the leaves were kept in warm water for $5 \mathrm{~min}$. The eggs were counted under a light microscope, using a $\times 160$ magnification. The experiment was conducted three times.

To examine the effect of bio-priming on Liromyza pupation and adult emergence, two days post infestation (dpi) with adult flies, the plants were removed from the oviposition cages, transferred into holding cages and watered using tap water for 4 days. At $96 \mathrm{hr}$ post infestation, the leaves were detached from the mother plant. The number of mines or larvae per leaf were counted and the leaves placed in $90 \mathrm{~mm}$ diameter Petri dishes; which were incubated under room conditions $(25 \pm$ $\left.2{ }^{\circ} \mathrm{C}\right)$. The pupae emerging from the leaves after leaf detachment were harvested at 24 and 48 hr using a Carmel brush; and the number of pupae collected at each harvest recorded. The harvested pupae were incubated on laboratory benches at $25 \pm 2{ }^{\circ} \mathrm{C}$, for ten days and the number of adults counted for three days following the onset of adult emergence. The experiment was conducted three times. 
Data analysis. The data collected were analysed using the SAS statistical software. Because the data from the three experimental repeats did not vary statistically, thus, they were pooled before conducting the analysis. With the exception of the number of root nodules, all data sets including the chlorophyll index, and fresh shoot and root weights were analysed using analysis of variance (ANOVA).

Prior to conducting ANOVA the chlorophyll index, and the fresh shoot and root weights were $\log$ transformed to obtain a normally distributed data with homogeneous variance. The treatment means were separated using Tukey's studentised range test. The number of root nodules and eggs was analysed using Kruskal-Wallis test and differences among treatment means separated using a Bonferroni test (SAS Institute, 1995).

The enzymatic indices were calculated using the formula:

Enzymatic index $=\underline{\text { Total diameter }(\text { final colony }+ \text { halo) }}$ Diameter of the colony

\section{RESULTS}

In vitro pathogenicity assay against Liriomyza leaf miners. Spore suspension of all tested endophytic fungal isolates had a negative effect on the viability of leaf miner larvae and the subsequent pupation, with blackening observed among dead larvae and pupae obtained from endophyte treated leaves (Fig. 1). In comparison with the negative control treatment, relatively fewer pupae emerged from endophyte treated leaves $(\mathrm{P}<0.001)$. Overall, larval development and pupation was suppressed by over $70 \%$, by a factor of 2.0-2.7 times over the non-treated leaves (Table 1).

Enzymatic profiles of bio-inoculants. No enzymatic activity was observed in the control plates (Fig. 2). However, a distinct zone of clearance was observed around the fungal colonies of the tested isolates and enzymatic assays, except for chitinase where no activity was noted (Table 2). Protease (1.22) and lipase (1.32) indices were higher than for cellulase (1.06) index $(\mathrm{F}=30.65 ; \mathrm{df}=2 ; \mathrm{P}<0.0001)$. Metarhizium anisopliae (1.24) exhibited the highest enzymatic index; followed by Trichoderma (1.16) and Beauveria (1.12) $(\mathrm{F}$ $=154.58 ; \mathrm{df}=2 ; \mathrm{P}<0.0001)$.

Although lipase activity was exhibited by all isolates, only activity indices of M2RT4 and S4ST7 could be statistically computed. Protease, cellulase and lipase enzymatic indices, however, were dependent on the interaction between the isolate and substrate $(\mathrm{F}=28.04 ; \mathrm{df}=3 ; \mathrm{P}<0.0001)$. Protease $(\mathrm{F}=$ 22.99; $\mathrm{df}=2 ; \mathrm{P}<0.0001)$ and cellulase $(\mathrm{F}=$ 28.34; $\mathrm{df}=2 ; \mathrm{P}<0.0001)$ indices for $\mathrm{S} 4 \mathrm{ST} 7$ were significantly higher than for S4SU1 and M2RT4 (Fig. 3). For lipase activities, indices for M2RT4 and S4ST7 were statistically similar $(\mathrm{F}=1.13 ; \mathrm{df}=1 ; \mathrm{P}=0.3080)$.

Bio-priming and seed viability, seedling growth and nodulation. Overall, seed viability was not affected by bio-priming $(\mathrm{P}=0.2363)$.

TABLE 1. Effect of fungal endophytes on French bean leaf miner pupal emergence, 4 days after immersing larval-infested leaves in spore suspension of $10^{8}$ conidia $\mathrm{ml}^{-1}$

\begin{tabular}{llcc}
\hline Isolate & Fungal identity & Pupal emergence* & Suppression factor \\
\hline Control & Water & 64.5 & - \\
S4SU1 & Beauveria bassiana & 28.2 & 2.0 \\
M2RT4 & Trichoderma asperellum & 12.3 & 2.5 \\
S4ST7 & Metarhizium anisioplaie & 2.7 & 2.7 \\
\hline
\end{tabular}

*Represents the average percentage of leaf miner larvae that pupated after treatment, while suppression factor represents the factor by which an isolate prevented larval pupation compared to the control treatment 


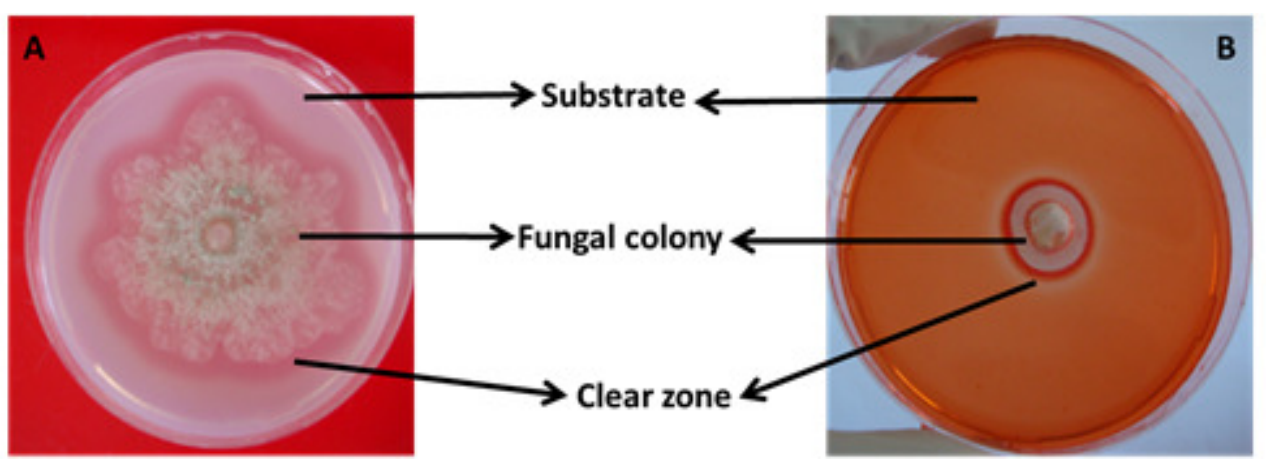

Figure 2. Agar plates (1-2 weeks-old) demonstrating secretion of extracellular enzymes by endophytic fungal isolates. $\mathrm{A}=$ protease activity (Trichoderma asperellum), and $\mathrm{B}=$ cellulase activity (Beauveria bassiana).

TABLE 2. Extracellular enzyme activities of fungal endophytes

\begin{tabular}{lcccc}
\hline Isolate & Protease & Cellulase & Lipase & Chitinase \\
\hline Trichoderma asperellum & + & + & + & - \\
Beauveria bassiana & + & + & + & - \\
Metarhizium anisopliae & + & + & + & - \\
\hline
\end{tabular}

“+” signifies enzymatic activity, while “ _ " implies no enzymatic activity

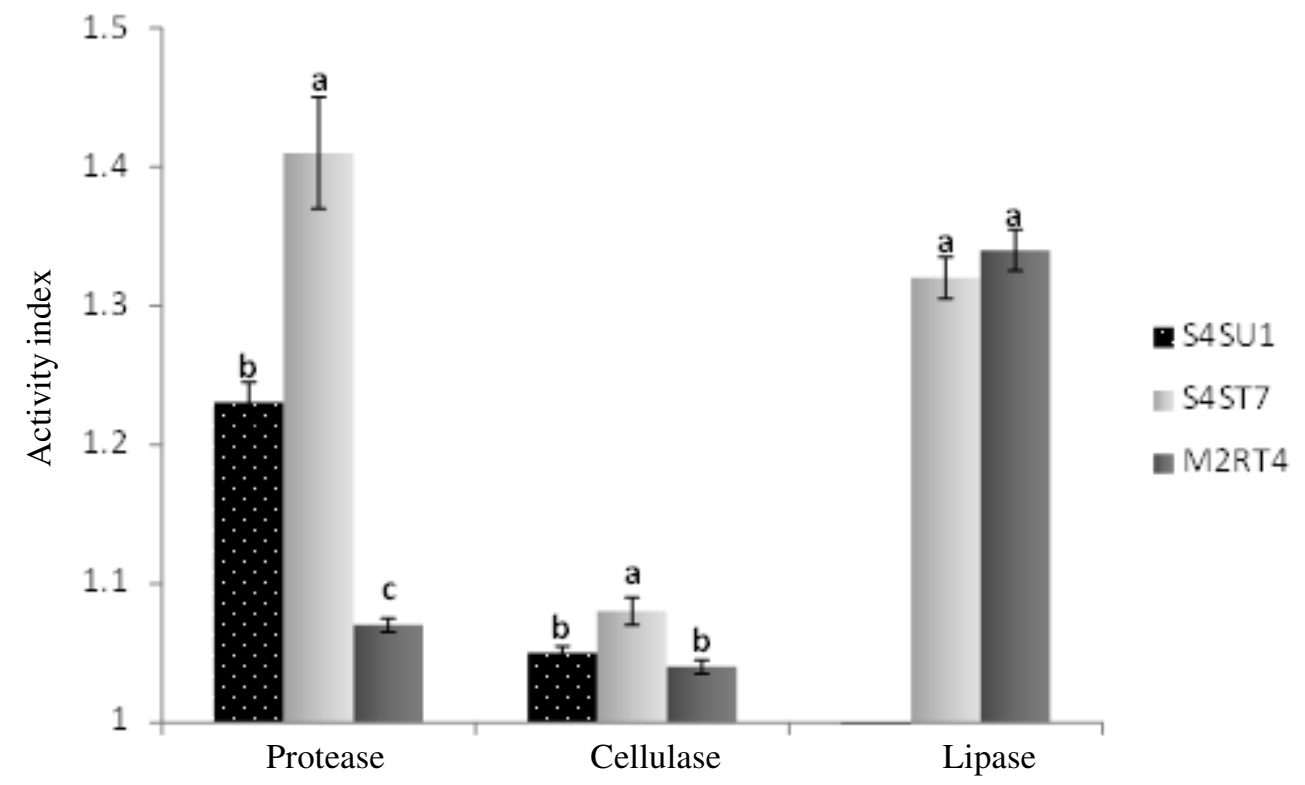

Figure 3. Enzyme activity indices of bio-inoculants, Beauveria bassiana (S4SU1), Metarhizium anisopliae (S4ST7) and Trichoderma asperellum (M2RT4). For each enzyme, bars with similar letters are not significantly different at $\mathrm{P}<0.05$ (Tukey's studentised range test). 
Pooled data across the three experimental trials showed that neither the rate of seed germination, nor the proportion of germinated seeds were influenced by bio-priming $(\mathrm{F}=$ $0.33 ; \mathrm{df}=3 ; \mathrm{P}=0.09$ ). Three days after inoculation, over $80 \%$ of inoculated seeds had germinated, with the proportion of germinated seeds varying from 88 to $98 \%$; but being equal across treatments (Table 3 ).

Although bio-priming seeds with endophytic fungi had a positive effect on seedling growth, the endophytic strains differentially supported shoot and root growth and nodulation. The fresh shoot weight of $T$. asperellum (M2TR4)- and B. bassiana (S4SU1)-treated bean seedlings were significantly higher than for $M$. anisopliae (S4ST7)-treated plants $(\mathrm{F}=6.62 ; \mathrm{df}=3$; $\mathrm{P}=0.0003$ ).

The fresh roots of seedlings treated with S4ST7 were the heaviest; followed by S4SU1; while the lightest was for the control (water- primed seedlings $)(\mathrm{F}=5.13 ; \mathrm{df}=3 ; \mathrm{P}=0.0021)$ (Table 3). All endophyte treated bean seedlings had significantly more root nodules than the control seedlings $(\mathrm{F}=4.22 ; \mathrm{df}=3 ; \mathrm{P}=$ 0.0068).

A positive correlation was observed between root weight and number of nodules $(\mathrm{r}=0.76)$; with heavier roots containing significantly more nodules than those with lighter roots (Table 4). Similarly, the chlorophyll index of bean leaves was affected by endophyte treatment, with the leaves of M2RT4- and S4SU1-treated bean seedlings containing higher indices than water-primed seedlings $(\mathrm{F}=3.3 ; \mathrm{df}=3 ; \mathrm{P}=0.0203)$ (Table $3)$.

Bio-priming and oviposition, larval pupation and adult emergence. About 12.0 eggs were laid per plant by the Liriomyza insects, with the number of eggs laid by Liriomyza sativae (12.8) being more than that

TABLE 3. Effect of bio-priming Phaseolus vulgaris seeds on seedling biomass, nodulation and chlorophyll index, six weeks after soaking seeds in fungal suspension containing 108 conidia/ $\mathrm{ml}$ for $4 \mathrm{hr}$

\begin{tabular}{lccccc}
\hline Treatment & Viability* $(\%)$ & FSW $(\mathrm{g})$ & FRW $(\mathrm{g})$ & No. of root nodules & Chlorophyll index \\
\hline Control & $97.7(2.7)$ & $7.2(0.3) \mathrm{b}$ & $4.5(0.3) \mathrm{c}$ & $44.1(3.4) \mathrm{b}$ & $38.0(0.6) \mathrm{b}$ \\
M2RT4 & $89.4(6.9)$ & $9.1(0.4) \mathrm{a}$ & $5.7(0.4) \mathrm{bc}$ & $69.6(6.1) \mathrm{a}$ & $39.6(0.6) \mathrm{a}$ \\
S4SU1 & $87.7(6.0)$ & $9.1(0.4) \mathrm{a}$ & $5.9(0.5) \mathrm{b}$ & $66.6(5.9) \mathrm{a}$ & $39.5(0.6) \mathrm{a}$ \\
S4ST7 & $89.7(4.2)$ & $6.6(0.6) \mathrm{b}$ & $8.2(0.7) \mathrm{a}$ & $74.1(8.3) \mathrm{a}$ & $38.5(0.6) \mathrm{ab}$ \\
\hline
\end{tabular}

*Represents the proportion of seeds that germinated. M2RT4, S4SU1 and S4ST7 treatments represent Trichoderma asperellum, Beauveria bassiana and Metarhizium anisopliae inoculants, respectively. For each parameter, mean values $( \pm \mathrm{SE})$ in columns followed by the same letters are not significantly different at $\mathrm{P}<0.05$ (Tukey's studentised range test)

TABLE 4. Pearson's correlation coefficient values showing relationship between the number of root nodules and fresh root weight

\begin{tabular}{|c|c|c|c|c|c|}
\hline & NRN & Control & S4SU1 & S4ST7 & M2RT4 \\
\hline FRW (g) & 0.7621 & 0.9057 & 0.7718 & 0.6115 & 0.8231 \\
\hline Significance level & & $<.0001$ & $<.0001$ & 0.0201 & $<.0001$ \\
\hline
\end{tabular}

FRW and NRN represent the Fresh root weight and number of root nodules; M2RT4, S4SU1 and S4ST7 treatments represent Trichoderma asperellum, Beauveria bassiana and Metarhizium anisopliae inoculants, respectively 
of L. trifolii (11.4); but not significantly different $(\mathrm{F}=0.66 ; \mathrm{df}=1 ; \mathrm{P}=0.418)$. However, there was neither an effect of endophyte seed priming on leaf miner fecundity $(\mathrm{F}=2.36 ; \mathrm{df}=3 ; \mathrm{P}=0.0781)$, nor any interaction between species and endophyte treatment $(\mathrm{F}=1.26 ; \mathrm{df}=3 ; \mathrm{P}=0.2933)$. Although the number of eggs laid on $B$. bassiana- treated plants was less than those laid on the other treatments, no statistical difference was observed across treatments $(\chi$ $=7.24 ; \mathrm{df}=3 ; \mathrm{P}=0.0646$ ) (Table 5).
Results of pooled data across the three experimental trials showed that bio-priming French bean seeds with fungal endophytes had a detrimental effect on larval hatching $(\mathrm{F}=$ 17.21; df $=3 ; \mathrm{P}<0.0001)$; but was not dependent on leaf miner species $(\mathrm{F}=2.6$; $\mathrm{df}$ $=1 ; \mathrm{P}=0.1105)$. The total number of larvae counted from the leaves of B. bassianatreated seedlings was significantly lower than that of water-primed seedlings by a factor of $2.5(\mathrm{~F}=16.3 ; \mathrm{df}=1 ; \mathrm{P}<0.0001)$ (Table 5). Consequently, the number of mines observed

TABLE 5. Effect of fungal endophyte seed treatment on pupation of Liriomyza leaf miners

\begin{tabular}{lcllc}
\hline Treatment & Number of eggs & Larvae T & \multicolumn{1}{c}{ Pupae 1 } & Pupae T \\
\hline 1. Control & $12.0(1.6) \mathrm{a}$ & $71.8(8.3) \mathrm{a}$ & $31.7(4.9) \mathrm{a}$ & $80.8(5.4) \mathrm{a}$ \\
2. M2RT4 & $14.5(1.5) \mathrm{a}$ & $65.2(8.9) \mathrm{a}$ & $20.6(4.8) \mathrm{ab}$ & $55.7(6.1) \mathrm{b}$ \\
3. S4ST7 & $13.5(2.2) \mathrm{a}$ & $55.8(7.2) \mathrm{a}$ & $28.4(3.4) \mathrm{a}$ & $66.2(4.8) \mathrm{ab}$ \\
4. S4SU1 & $9.0(1.1) \mathrm{a}$ & $28.4(3.9) \mathrm{b}$ & $14.7(2.5) \mathrm{b}$ & $45.5(6.2) \mathrm{c}$ \\
\hline
\end{tabular}

M2RT4, S4SU1 and S4ST7 treatments represent Trichoderma asperellum, Beauveria bassiana and Metarhizium anisopliae bio-incoulants, respectively. Total number of larvae (LarvaeT) was scored at 4 days post infestation with adult flies. Pupae 1 and pupaeT represent the total number of pupae harvested on $1^{\text {st }}$ and $3^{\text {rd }}$ day after crop harvest. For each parameter, mean values $( \pm S E)$ in columns followed by the same letters are not significantly different at $\mathrm{P}<0.05$, Tukey's studentised range test.

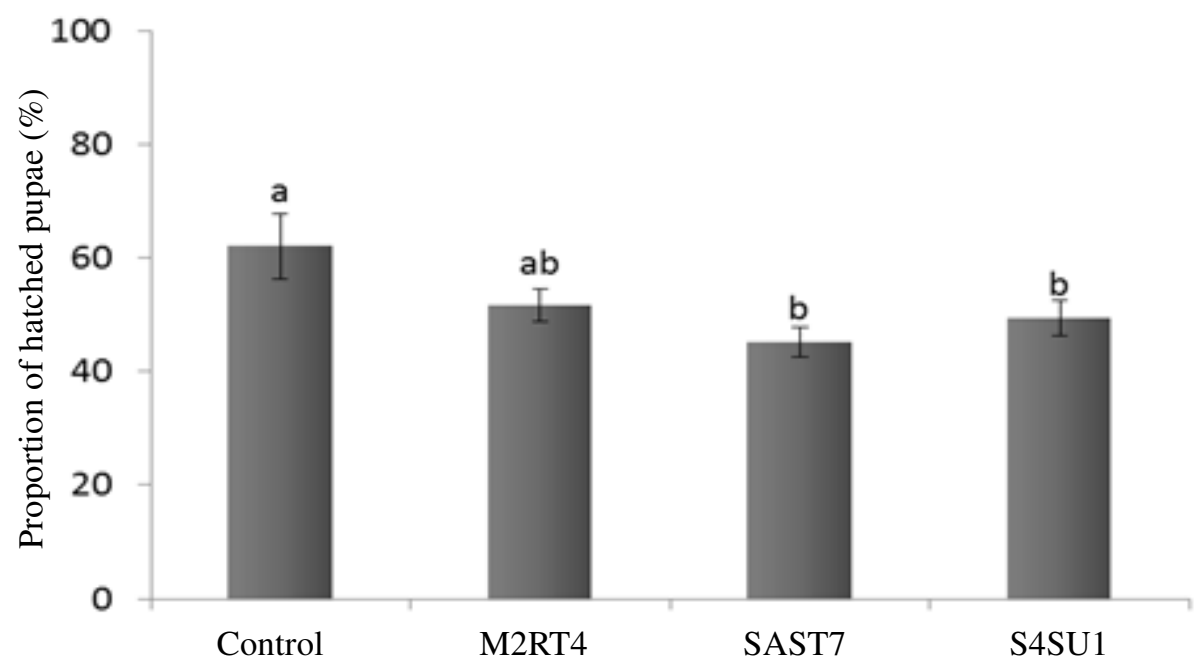

Figure 4. Effect of fungal endophyte seed treatment on Liriomyza adult emergence, 10 days after pupal harvest. Bars followed by the same letters are not significantly different at P d" 0.05 , Tukey's studentised range test. M2RT4, S4SU1 and S4ST7 treatments represent Trichoderma asperellum, Beauveria bassiana and Metarhizium anisopliae bio-incoulants, respectively. 
on the leaves of $B$. bassiana-treated plants was less than that on the other treatments. No interaction was observed in larval number between species and endophyte seed treatment $(\mathrm{F}=2.16 ; \mathrm{df}=3 ; \mathrm{P}=0.098)$.

Pupation was delayed by endophyte seed treatment (Table 5). On the first day of harvest, the number of pupae collected from the $T$. asperellum and B. bassiana- treated plants was similar but less than that harvested from the controls by 1.5-2.2 fold $(\mathrm{F}=20.0 ; \mathrm{df}=3 ; \mathrm{P}<$ 0.0001) (Table 5).

By the third day, the total number of pupae harvested from the control plants was significantly higher than that of the $B$. bassiana- treated seedlings by a factor 1.8 ; but was imilar to the other treatments $(\mathrm{F}=$ 17.07; $\mathrm{df}=3 ; \mathrm{P}<0.0001)$. Similarly, adult emergence was delayed for pupae harvested from the B. bassiana-treated plants. By the 7 th day post pupal harvest, fewer adults emerged from the B. bassiana-treated seedlings $(6.2 \%)$ compared to the $\mathrm{T}$. asperellum (13.4\%), M. anisopliae (16.9\%) and water $(20.3 \%)$ treated seedlings $(\mathrm{F}=45.1$; $\mathrm{df}=3 ; \mathrm{P}<0.0001)$. By the $10^{\text {th }}$ day postharvest, a significantly lower number of pupae had hatched from the B. bassianatreated and $M$. anisopliae-treated plants $(<50 \%)$ when compared to the untreated ones $(>60 \%)(\mathrm{F}=17.55 ; \mathrm{df}=3 ; \mathrm{P}<0.0001)$ (Fig. $4)$.

\section{DISCUSSION}

In the present study, all tested isolates synthesized at least three enzymes on test substrate signifying that they may be able to hydrolyse and utilise insect cuticle for their nutritional requirements. With the exception of $B$. bassiana, which produced limited amounts of lipase without a clear halo zone, all isolates produced quantifiable amounts of protein-, lipid- and polysaccharide-hydrolysing enzymes (Table 2). Similarly, previous research findings showed that different strains of entomopathogenic fungi and Trichoderma spp. frequently display great genetic and biochemical versatility with the types and amounts of extracellular enzymes secreted noted to depend on the fungal species and strain pathogenicity (Aslam et al., 2010; Mustafa and Kaur, 2010; Fernandes et al., 2012).

Thus, the differential utilisation of the various substrates observed in the present study may be indicative of their role as host range determinants. Whether such activities can be systemically induced in the leaves by the endophytes that colonise the roots remains to be investigated.

Research indicates that fungi, especially the entomopathogens, have negative effects on insect due to the production of extracellular hydrolytic enzymes (Strasser et al., 2000; Miller et al., 2002; Quesada-Moraga and Vey, 2004).

Pathogenicity assessment revealed that the screened bio-inoculants were highly toxic to leaf miner larvae following the submersion of larval-infested leaves in spore suspension (Table 1), reaffirming the insecticidal properties of the two entomopathogenic isolates, B. bassiana and M. anisopliae. Although the cause of larval mortality was not ascertained in this study, it is speculated that the detrimental effects of these endophytic fungal isolates, including larval development retardation, blackening and mortality, may have been due to antibiosis and direct parasitism under the present mode of testing.

A number of studies show that potent toxins, though variable in the types and quantities, are produced by most fungi and have differential activities in deterring insect feeding, retarding insect development and survival (Strasser et al., 2000; Miller et al., 2002; Quesada-Moraga and Vey, 2004). Most likely, such toxic secondary metabolites were produced in the media during the culture period and indirectly affected the exposed larvae.These types of in vitro studies reveal a possible role of fungal metabolites in regulating pest population but they probably have little 
relevance as components of in planta suppression of insect pests.

This study has showed that priming French bean seeds with the three bio-inoculants, Trichoderma asperellum (M2TR4), Metarhizium anisopliae (S4ST7) and Beauveria bassiana (S4SU1) strains neither affected seedling emergence nor the proportion of germinated seeds. This implies that bio-priming French bean seeds with these antagonistic endophytic fungi does not interfere with the physiological processes of seed germination; nor with seedling development. They are, therefore, beneficial to both growth processes during early stages of crop establishment.

With respect to biomass, the study has revealed that bio-priming French bean seeds with the three fungal inoculants increases seedling growth, with S4SU1 and M2RT4 isolates enhancing root biomass while S4SU1 and S4ST7 promoting shoot growth (Table 3). The ability of beneficial fungal microbes to enhance plant growth has been reported in beans (El-bab et al., 2013; Labidi et al., 2015) and other crops (Vila-Aiub et al., 2005; Vinale et al., 2008; Paparu et al., 2009). Under field conditions, for example, El-bab et al. (2013) showed that coating green pinto bean seeds with either Trichoderma harzianum or T. viride enhanced seedling emergence. The authors further revealed that the two bio-inoculants significantly increased vegetative growth parameters and total nitrogen of green bean pods (El-bab et al., 2013), which is in agreement with the enhancement of biomass accumulation observed in the present study.

For the first time, we report the ability of the endophytic strains M2RT4 and S4SU1 to enhance the chlorophyll content of leaves sampled from treated bean seedlings; as well as promote better nodulation in primed seedlings. High chlorophyll content and numerous root nodules are usually indicative of higher photosynthetic rate and accumulation of nitrogen (Pinkard et al., 2006), and/or increased nitrogen fixation in the soil ultimately resulting to better establishment and growth of the seedlings. According to Pinkard et al. (2006), the chlorophyll content of a leaf is linearly correlated with nitrogen content of Eucalyptus nitens and E. globulus.

Liriomyza satvae and L. trifolii females oviposited in all plants irrespective of the treatment (Table 5), ultimately leading to equal number of eggs laid per treatment. This finding suggests that bio-priming French bean seeds with the selected bio-inoculants has no detrimental effect on deterring adult flies from feeding and ovipositing on treated seedlings.

Although no research exists on the effect of endophytes on the oviposition rate of vegetable leaf miners, field studies reveal that females of the horse chestnut leaf miner (Cameraria sp.) are unable to discriminate between endophyte- and non-infected Emory oak leaves (Faeth and Hammon, 1996). Nonetheless, the systemic effects of endophytic fungi on oviposition of other insect species have been demonstrated before (Jallow et al., 2008).

This study has demonstrated that endophyte seed priming delays pupation in second larval instar of L. Sativa and L. trifolii larvae. This signifies that the bio-inoculants used in the study had a negative effect on larval development. Consequently, the total number of pupae and adults flies that were estimated from endophyte treated seedlings were fewer than for the controls. Similarly, Akutse et al. (2013) reported that the life-history parameters of $L$. huidobrensis were significantly affected when the flies were fed on endophyte-treated faba bean seedlings. Similarly Akutse et al. (2013) observed Hypocrea lixii to outperform other endophytic strains in reducing $L$. huidobrensis population. We observed that the antagonistic effects of the three endophytic fungi were strain dependent. Strains of $B$. bassiana (S4SU1) and T. asperellum (M2RT4) had a stronger effect on deterring leaf miner larval feeding, with the number of mines 
observed on S4SU1- and M2RT4-primed seedlings being less than that of $M$. anisopliae (S4ST7) primed seedlings by a factor of 3 . Accordingly, the leaves of treated bean seedlings had reduced leaf miner numbers as well as appeared less damaged. Most likely, such a treatment would provide effective control and thus highly beneficial during the start of the growing season when seedlings are most sensitive to insect attack.

\section{CONCLUSION}

This study has clearly demonstrated that Beauveria bassiana, Metarhizium anisopliae and Trichoderma asperellum bioinoculants play a regulatory role in French bean growth. The results further indicate that the bio-inoculants have no negative effects on the germination of French bean seeds, which in turn promote rapid early seedling establishment and the ability to overcome stress factors. Whereas none of the isolates showed detrimental effects on seed viability and emergence of bean seedlings, bio-priming also boosted $P$. vulgaris growth, consequently altering its interaction and response to leaf miner infestation, feeding and damage to treated seedlings. This suggests that the bio-inoculants used in this study could be safely used for minimising leaf mining damages and associated yield losses in French beans. However, further studies should be undertaken to elucidate the mechanisms involved in plant growth promotion as well as their utilisation as potential nitrogen fixers.

\section{ACKNOWLEDGMENT}

This research was funded by the Centre for Development Research (ZEF) through financial support from the Bundesministerium für Wirtschaftliche Zusammenarbeit (BMZ), Germany. We thank the staff of the International Centre of Insect Physiology and Ecology (ICIPE) and the University of Bonn for technical assistance.

\section{REFERENCES}

Akello, J. 2012. Biodiversity of fungal endophytes associated with maize, sorghum and Napier grass and the influence of biopriming on resistance to leaf mining, stem boring and sap sucking insect pests. $\mathrm{PhD}$. Thesis, University of Bonn, Gremany. 86pp.

Akello, J. and Sikora, R. 2012. Systemic acropedal influence of endophyte seed treatment on Acyrthosiphon pisum and Aphis fabae offspring development and reproductive fitness. Biological Control 61:215-221.

Akutse, K.S., Maniania, N.K., Fiaboe, K.K.M., Van den Berg, J. and Ekesi, S. 2013. Endophytic colonization of Vicia faba and Phaseolus vulgaris (Fabaceae) by fungal pathogens and their effects on the lifehistory parameters of Liriomyza huidobrensis (Diptera: Agromyzidae). Fungal Ecology 6:293-301.

Andrew, N.R. and Hughes, L. 2005. Diversity and assemblage structure of phytophagous Hemiptera along a latitudinal gradient: predicting the potential impacts of climate change. Global Ecology and Biogeography 14:249-262.

Andro, T., Chambost, J.P., Kotoujansky, A., Cattaneo, J., Bertheau, Y., Barras, F., Van Gijsegem, F. and Coleno, A. 1984. Mutants of Erwinia chrysunthemi defective in secretion of pectinase. Journal of Bacteriology 160:1199-1203.

Aslam, N., Munir, A.S., Muhammad, A. and Amer, J. 2010. Expression pattern of Trichoderma cellulases under different carbon sources. Pakistan Journal of Botany 42:2895-2902.

Beebe, S.E., Rao, I.M., Blair, M.W. and Acosta-Gallegos, J. A. 2013. Phenotyping common beans for adaptation to drought. Frontiers in Physiology 4:35. http://doi.org/ 10.3389/fphys.2013.00035. 
Begum, M.M., Sariah, M., Puteh, A.B., ZainalAbidin, M.A., Rahman, M.A. and Siddiqui, Y. 2010. Field performance of bio-primed seeds to suppress Colletotrichum truncatum causing damping-off and seedling stand of soybean. Biological Control 53:18-23.

Birachi, E.A., Ochieng, J., Wozemba, D., Ruraduma, C., Niyuhire, M.C. and Ochieng, D. 2011. Factors influencing smallholder farmers' bean production and supply to market in Burundi. African Crop Science Journal 9:335-342.

Broughton, W.J., Hern'andez, G., Blair, M., Beebe, S., Gepts, P. and Vanderleyden, J. 2003. Beans (Phaseolus spp.) - model food legumes. Plant Soil 252:55-128.

Chabi-Olaye, A., Mujica, N., Löhr, B. and Kroschel, J. 2008. Role of agroecosystems in the abundance and diversity or Liriomyza leafmining flies and their natural enemies. In: Abstracts of the XXIII International Congress of Entomology, 6-12 July 2008. Durban, South Africa.

El-bab, F., Sh T. and El-Mohamedy, R.S.R. 2013. Bio-priming seed treatment for suppressive root rot soil borne pathogens and improvement growth and yield of green bean (Phaseulus vulgaris L.) in new cultivated lands. Journal of Applied Sciences Research 9:4378-4387.

Faeth, S.H. and Hammon, K.E. 1996. Fungal endophytes and phytochemistry of oak foliage: determinants of oviposition preference of leaf miners? Oecologia 108:728-736.

Faeth, S.H. and Hammon, K.E. 1997. Fungal endophytes in oak trees: experimental analyses of interactions with leafminers. Ecology 78:820-827.

Fernandes, E.G., Valério, H.M., Feltrin, T. and Van Der, S.T. 2012. Variability in the production of extracellular enzymes by entomopathogenic fungi grown on different substrates. Brazilian Journal of Microbiology 43:827-833.
Gange, A.C., Dey, S., Currie, A.F. and Sutton, B.C. 2007. Site- and species-specific differences in endophyte occurrence in two herbaceous plants. Journal of Ecology 95:614-622.

Hankin, L. and Anagnostaksis, L. 1975. The use of solid media for detection of enzyme production by fungi. Mycologia 47:597607.

Huong, T.T.L., Padgham, J.L. and Sikora, R.A. 2009. Biological control of the rice root knot nematode Meloidogyne graminicola on rice, using endophytic and rhizozphere fungi. International Journal of Pest Management 55:31-36.

Hsu, S.C. and Lockwood, J.L. 1975. Powdered chitin agar as a selective medium for enumeration of actinomycetes in water and soil. Applied Microbiology Journal 29:422426.

Jallow, M.F.A, Dugassa-Gobena, D. and Vidal, S. 2008. Influence of an endophytic fungus on host plant selection by a polyphagous moth via volatile spectrum changes. Arthropod-plant Interactions 2: 53-62.

Labidi, S., Jeddi, F.B., Tisserant, B., Yousfi, M., Sanaa, M., Dalpé, Y. and Sahraoui, A.L. 2015. Field application of mycorrhizal bioinoculants affects the mineral uptake of a forage legume (Hedysarum coronarium L.) on a highly calcareous soil. Mycorrhiza 25: 297-309.

Martinuz, A., Schouten, A., Menjivar, R.D. and Sikora, R.A. 2012a. Effectiveness of systemic resistance toward Aphis gossypii (Hom., Aphididae) as induced by combined applications of the endophytes Fusarium oxysporum Fo162 and Rhizobium etli G12. Biological Control 62:206-212.

Martinuz, A., Schouten, A. and Sikora, R.A. 2012b. Systemically induced resistance and microbial competitive exclusion: implications on biological control. Phytopathology 102:260-266.

Mathre, D.E., Callan, N.W., Johnston, R.H., Miller, J.B. and Schwend, A. 1994. Factors 
influencing the control of Pythium ultimum induced seed decay by seed treatment with Psudomonas aureofaciens AB254. Crop Protection 13:301-307.

Miller, J.D., MacKenzie, S., Foto, M., Adams, G.W. and Findlay, J.A. 2002. Needles of white spruce inoculated with rugulosinproducing endophytes contain rugulosin reducing spruce budworm growth rate. Mycological Research 106:471-479.

Mustafa, U. and Kaur, G. 2010. Studies on extracellular enzyme production in Beauveria bassiana isolates. International Journal of Biotechnology and Biochemistry 6:701-713.

Paparu, P., Dubois, T., Coyne, D. and Viljoen, A. 2009. Dual inoculation of Fusarium oxysporum endophytes in bananas: effects on plant colonization, growth and control of the root burrowing nematode and the banana weevil. Biocontrol Science and Technology 19:639-655.

Pill, W.G., Collins, C.M., Gregory, N. and Evans, T.A. 2011. Application method and rate of Trichoderma species as a biological control against Pythium aphanidermatum (Edson) Fitzp. in the production of microgreen table beets (Beta vulgaris $\mathrm{L}$.). Scientia Horticulturae 129:914-918.

Pinkard, E.A., Patel, V. and Mohammed, C. 2006. Chlorophyll and nitrogen determination for plantation-grown Eucalyptus nitens and E. globulus using a non-destructive meter. Forest Ecology and Management 223:211-217.

Quesada-Moraga, E. and Vey, A. 2004. Bassiacridin, a protein toxic for locusts secreted by the entomopathogenic fungus Beauveria bassiana. Mycological Research 108:441-452.

SAS Institute Inc. 1995. JMP Statistics and Graphic Guide, Version 9.4. SAS Institute, Inc., Cary, USA
Sierra, G. 1957. A simple method for the detection of lipolytic activity of microorganisms and some observations on the influence of contact between cells and fatty substrates. Antonie van Leeuwenhoek Ned Tijdschr Hyg 23: 15-22.

Sikora, R.A., Pocasangre, L., zum-Felde, A., Niere, B., Vu, T.T. and Dababat, A.A. 2008. Mutualistic endophytic fungi and in-planta suppressiveness to plant parasitic nematodes. Biological Control 46:15-23.

Strasser, H., Vey, A. and Butt, T.M. 2000. Are there any risks in using entomopathogenic fungi for pest control, with particular reference to the bioactive metabolites of Metarhizium, Tolypocladium and Beauveria species? Biocontrol Science and Technology 10:717-735.

Vila-Aiub, M.M., Gundel, P.E. and Ghersa, C.M. 2005. Fungal endophyte infection changes growth attributes in Lolium multiflorum Lam. Austral Ecology Journal 30:49-57.

Vinale, F., Sivasithamparam, K., Ghisalberti, E.L., Marra, R., Barbetti, M.J., Li, H., Woo, S.L. and Lorito, M. 2008. A novel role for Trichoderma secondary metabolites in the interactions with plants. Physiological and Molecular Plant Pathology 72:80-86.

Wagara, I.N. and Kimani, P.M. 2007. Resistance of nutrient-rich bean varieties to major biotic constraints in Kenya. African Crop Science Conference Proceedings 8: 2087-2090.

Wortman, S.C., Kirkby, A.R., Eledu, A.C. and Allen, J.D. 2004. Atlas of common bean (Phasealus vulgaris L.) production in Africa. Cali, Colombia: International Centre for Tropical Agriculture, CIAT. 